\title{
Role of Vitamin E as a Preventive measure Against Platelet Aggregation In Pregnancy Induced Hypertension
}

\author{
Kausar Aamir, Fatima Abid, Arfa Azhar
}

ABSTRACT

Objective: To correlate the preventive role of vitamin E levels and platelet count in patients with different grades of pregnancy induced hypertension. The secondary objective was to compare these grades with normal pregnant patients.

Study Design and Setting: This study was conducted in Obstetric OPD of Jinnah Postgraduate Medical Centre (JPMC), Karachi, from April 2002 through April 2004.

Methodology: The study group included 110 patients divided in three groups as Group A: $\mathrm{n}=40$ Normotensive patients, Group B: $n=40$ Mild hypertensive (test group I), Group C: $n=30$ Severe hypertensive (test group II). All women were advised not to take any multivitamin supplements.

Result: Serum alpha tocopherol (vitamin E) was significantly low in severe and mild cases $(0.32 \pm 0.00 \mathrm{mg} / \mathrm{dl}, 0.74 \pm 0.03$ $\mathrm{mg} / \mathrm{dl}$ respectively), when compared with normal pregnant women levels $(0.78 \pm 0.040)$. The decreased platelet count $(246820 \pm 1493.51)$ in mild cases and $(135460 \pm 387.2)$ in severe cases was significant $(\mathrm{P}<0.01)$ as compared to the normal pregnant women $(348000 \pm 574.35)$. The decrease platelet count values for severe cases were again significant $(\mathrm{P}<0.01)$ when compared with mild cases of PIH.

Conclusion: In patients with risk of preeclampsia adequate antioxidant nutrients may have a role in cessation of free radicalmediated cell disturbances, and thereby protecting against endothelial cell damage, which is the key factor in preeclampsia development.

Key words: Oxidative stress, Preeclampsia, Vitamin E

\section{INTRODUCTION:}

Pre-eclampsia is a distressing condition of pregnancy which presents with elevated maternal blood pressure, high protein in urine and body fluid retention, affecting around $2-5 \%$ of all pregnancies. Regarding the cause for the condition, various theories have been documented, however most prevalent factors which seem to play role are genetic and the placental dysfunction ${ }^{1}$.

Pre-eclampsia has a large spectrum of effects and potentially involves all maternal organ systems ${ }^{2}$. Many theories have proposed diverse pathological changes including, abnormal trophoblast invasion in placental bed, coagulation abnormalities, immunologic phenomena, genetic predisposition and vascular endothelial damage. Defective placentation creates hypoxic condition which in turn increases oxidative stress in pre-eclampsia ${ }^{3}$. Increased production of oxygen radicals damage endothelial cells by enhancing the

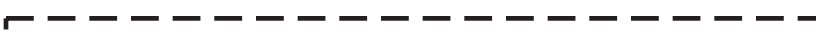

I Kausar Aamir Department of Pharmacology

JPMC, Karachi

I

Fatima Abid,

Department of Physiology

I JSMU, Karachi

I Arfa Azhar

Senior Instructor, Biological and Biomedical Sciences

Department, Aga Khan University Hospital, Karachi

Email: arfa.amjee@gmail.com

Received: 24-10-2018

Accepted: 06-05-2019 expression of adhesion molecules and causing imbalance of arachidonic acid metabolites ${ }^{4}$.

The hydroxyl radical $\left(\mathrm{OH}^{-}\right)$can initiate lipid peroxidation of cell membrane lipids, causes intermediate metabolites which results in an autocatalytic chain reaction of lipid peroxidation (Lipid-OOH) ultimately causes membrane damage and eventually, cell death. In addition, lipid peroxides impair endothelial prostacyclin synthesis ${ }^{5}$. In the light of these evidences many researchers have documented elevated lipid peroxidase reaction products in the preeclamptic subjects ${ }^{6}$.

The increased lipid peroxide component is found to favor production of platelet derived thromboxane $\left(\mathrm{TXA}_{2}\right)$ above vascular prostacyclin $\left(\mathrm{PG}_{2}\right)$ production ${ }^{4}$.

Pre-eclampsia has been associated with alterations in the prostacyclin $\left(\mathrm{PG}_{2}\right) /$ thromboxane $\left(\mathrm{TXA}_{2}\right)$ ratio thus increasing vasoconstrictor activity and platelet aggregation. Hence, alteration in $\mathrm{PG}_{2} / \mathrm{TCA}_{2}$ ratio precedes the onset of clinical symptoms. Since endothelial cell injury also, decreases prostacyclin synthesis, an increase in peripheral vascular resistance and platelet aggregation occurs. All of these changes may contribute to the pathogenesis of $\mathrm{PE}^{7}$.As it is known that the genesis of free radicals is the main factor in advent of extensive pathogenic events of pre-eclampsia, hence, free radicals scavengers (antioxidants) might be tried for therapy or prophylaxis. Antioxidant nutrients counter act the activity of free radicals in the body hence protecting peroxidation of lipids caused by free radicals ${ }^{8}$. It has been 
observed that antioxidant utilization is enhanced with increased free radical levels of antioxidants due to compensatory mechanism against oxidative stress ${ }^{9}$. Among several antioxidants Vitamin E has gained attention due to its activity against oxidative stress, lipid peroxidation and platelet aggregation ${ }^{10}$, which are the key factors of preeclamptic development.

Alpha tocopherol represents the principal form of the tocopherols in animal tissue. However, recent evidence shows that gamma tocopherols and tocotrienols exhibit much enhanced activity against oxygen radicals in comparison to other forms ${ }^{11}$. Research experiments prove that vitamin E, working as an antioxidant acts as a chain breaking agent which withhold the membrane damage owing to oxidation more effectively than antioxidants which are water soluble like vitamin $\mathrm{C}$, which deals with only liquid radicals, having no effect on membrane related radicals which carry chains ${ }^{6}$.Vitamin $\mathrm{E}$ has also been found to amend adherence and aggregation of platelets hereby preventing the fatty streak progression and cell proliferation in a lesion to advance stage. Other important functions of Vitamin $\mathrm{E}$ include its ability to increase the activity of phospholipase $\mathrm{A}_{2}$ and cyclooxygenase-1, which causes the release of prostacyclin. Investigations also show the inhibitory effect of vitamin $\mathrm{E}$ on platelet aggregation through protein kinase $\mathrm{C}$ inhibition and nitric oxide synthase activation ${ }^{10}$. Vitamin $\mathrm{E}$ usage was associated with better endothelial function and less placental dysfunction ${ }^{12}$.

Based upon this hypothesis our study was designed to investigate serum levels of vitamin $\mathrm{E}$ in patients with different grades of pregnancy induced hypertension i.e. mild and severe and to compare them with normal pregnancy i.e. control.

\section{METHODOLOGY:}

Nearly 200 pregnant women visiting the Obstetric OPD of Jinnah Postgraduate Medical Centre (JPMC), Karachi, for perinatal care, were recruited for this study from April 2002 to April 2004. Written consent was taken from each participant. The study was approved by Institutional Review board. The diagnosis of pre-eclampsia was established according to predefined criteria of "The American College of Obstetricians and Gynecologists (ACOG)". Pre-eclampsia was classified as mild unless one or more of the following signs or symptoms were present, which changed the mild form of pre-eclampsia to severe form. In this: Systolic blood pressure $=160 \mathrm{mmHg}$ or $110 \mathrm{mmHg}$ diastolic on two occasion 6 hours apart, Oliguria 24 hours (urinary output $<400$ to $500 \mathrm{ml}$ ): Cerebral or visual disturbances: Pulmonary edema or cyanosis: epigastric or right upper quadrant pain and impaired liver function of unclear cause or thrombocytopenia. Out of 200 patients 90 patients did not follow up till the end of study period due to unexplained reasons. Finally 110 patients were followed and divided into three groups as:
Group A: $(\mathrm{n}=40)$ Normotensive patients (normal cases) i.e. pregnant women $>20$ weeks gestation.

Grpup B: $(\mathrm{n}=40)$ Mild hypertensive $>140 / 90 \mathrm{mmHg}$ (test group I) i.e. pregnant women $>20$ weeks gestation.

Group C: $(\mathrm{n}=40)$ Severe hypertensive $>160 / 110 \mathrm{mmHg}$ (test group II) i.e. pregnant women $>20$ weeks gestation.

The pregnant females with maternal age of 15-38 years, gestational age 20-42 weeks and singleton pregnancy were included in this study. A predesigned proforma was used to record all important information related to personal history, maternal age, weight, height, systolic and diastolic blood pressure, parity, gestational age, any underlying illness, drug abuse history, family history of PIH or any complications occurred in previous pregnancies etc. Recent dietary intake was also recorded.Women having a history of vitamin supplementation before pregnancy, those with history of essential hypertension or high blood pressure due to kidney disease, endocrine disorder, any type of anemia, or any other chronic disease), multiple pregnancies and abnormal levels of serum creatinine (i.e. $1.5 \mathrm{mg} / \mathrm{dl}$ ) were excluded from the study.For sampling, fasting venous samples of blood were taken and stored in tubes coated with heparin. Plasma separation was done by centrifuge method and initially stored at $-80^{\circ} \mathrm{C}$ to be analyzed later but within 1 week. á-tocopherol level was assayed by means of HPLC (high pressure liquid chromatography). Platelet count was done by fractional centrifugation after citric acid blood coagulation. A 24 hour urine sample was collected for proteinuria estimation by urine dipstick method.All the categorical parameters were analyzed with the help of by Chi-square test on SPSS version 22.

\section{RESULTS:}

Table 1 shows the mean maternal age, weight, height, gestational age and birth weight of normal pregnant and pregnancy induced hypertensive women. The mean maternal age of the severe cases of pregnancy induced hypertensive was $20.33 \pm 0.77$ years which was significantly $(\mathrm{P}<0.01)$ low as compared to mild cases i.e. $23.37 \pm 0.75$ years and highly significant $(\mathrm{P}<0.001)$ when compared to the control cases i.e. 25.0 \pm 0.6 years. The weight of normal pregnant women were $60.4 \pm 0.5 \mathrm{Kg}$ while mean weight of the mild and severe cases of pregnancy induced hypertensive women were $58.05 \pm 0.4 \mathrm{Kg}$ and $56.6 \pm 0.36 \mathrm{Kg}$ respectively. There was no increase in the mean weight of the cases of PIH as compared to the normal cases, because of their comparative lower gestational ages which were $33.63 \pm 0.23$ and $31.16 \pm 0.5$ weeks in mild and severe cases of pregnancy induced hypertension. The mean gestational age of the controls were $36.6 \pm 0.37$ weeks. The mean height of all respective groups were non-significant. The mean birth weight of mild cases was $2.924 \pm 0.019 \mathrm{Kg}$ and severe group was $2.391 \pm 0.067$ $\mathrm{Kg}$, cases were highly significantly decreased $(\mathrm{P}<0.001)$ as compared to birth weight of normal pregnant controls i.e. $3.100 \pm 0.024$. 
Role of Vitamin E as a Preventive measure Against Platelet Aggregation In Pregnancy Induced Hypertension

Table 2 compares the blood pressure and proteinuria among three groups. The increase in systolic $(144.5 \pm 1.11 \mathrm{mmHg})$ and diastolic $(93.0 \pm 0.8 \mathrm{mmHg})$ blood pressure of mild cases and systolic $(172.6 \pm 3.31 \mathrm{mmHg})$ and diastolic $(127.5 \pm 2.07$ $\mathrm{mmHg})$ of severe cases were highly significant $(\mathrm{P}<0.001)$ when compared to controls: systolic $(121 \pm 1.69 \mathrm{mmHg})$ and $(77.7 \pm 1.11 \mathrm{mmHg})$. The increase in the systolic and diastolic blood pressure values for severe cases (group C) were again highly significant $(\mathrm{P}<0.001)$ when compared with the mild cases of PIH. Proteinuria was detected in $3(7.5 \%)$ cases of normal pregnant women, $21(52.5 \%)$ cases of mild PIH and $30(100 \%)$ cases of severe PIH women.

Table 3 compares the antioxidant nutrient profile and platelet count values among the three groups. Serum alpha tocopherol (vitamin E) was significantly low in severe and mild cases $(0.32 \pm 0.00 \mathrm{mg} / \mathrm{dl}, 0.74 \pm 0.03 \mathrm{mg} / \mathrm{dl}$ respectively), when compared with normal pregnant women levels $(0.78 \pm 0.040)$. The decreased platelet count $(246820 \pm 1493.51)$ in mild PIH cases and (135460 \pm 387.2$)$ in severe cases were significant $(\mathrm{P}<0.01)$ as compared to the normal pregnant women $(348000 \pm 574.35)$. The decrease in the platelet count values for severe cases were again significant $(\mathrm{P}<0.01)$ when compared with mild cases of PIH.

\section{DISCUSSION:}

Pre-eclampsia is a major contributor to maternal and fetal mortality and morbidity. Its incidence and related maternal mortality is high in third world countries due to lack of antenatal care, poor socio-economic conditions and female illiteracy levels. ${ }^{13}$ Oxidative stress has been implicated in the pathophysiology of pre-eclampsia. Also, the early stages of preeclamptic development are marked by enhanced activity of maternal clotting mechanism along with raised endothelial sensitivity to vasopressive agents. Physiologic irregularities of pre-eclampsia has been attributed to abnormalities in endothelial cells of maternal vessels due to emergence of free radicals from defective placenta. As a result of ongoing pathology in the vessels, the release of vaso-relaxing agents decreases, the process of vasoconstriction rise up, local anticoagulant levels goes down and pro-coagulant activity and production increases. Hence, the pathophysiology of preeclampsia revolves around these defective endothelial cells of maternal circulatory system. ${ }^{14}$

Under normal conditions healthy endothelium withstand platelet aggregation and coagulation on its surface ${ }^{15}$. This ability of resistance is due to endothelial cell dependent activation of potent circulating anticoagulant. ${ }^{16}$

Recently, much research is underway among preeclamptic women regarding the increased concentration thromboxane A2, which is a strong platelet aggregating agent and a dynamic vasoconstrictor, in comparison to decrease levels of prostacyclin, a vasodilator and suppresser of platelet activity. ${ }^{4}$ Preventing PIH is one of the major goals of treating pre-eclampsia. Recent notion regarding increased usage of
Table-1: Maternal Age, Weight, Height, Gestational Age And Birth Weight Of Normal Pregnant And Pregnancy Induced Hypertensive Women

\begin{tabular}{|l|c|c|c|}
\hline \multicolumn{1}{|c|}{ Parameters } & $\begin{array}{c}\text { Normal cases } \\
(\mathbf{n = 4 0})\end{array}$ & $\begin{array}{c}\text { Mild cases } \\
(\mathbf{n}=\mathbf{4 0})\end{array}$ & $\begin{array}{c}\text { Severe cases } \\
(\mathbf{n}=\mathbf{3 0})\end{array}$ \\
\hline Maternal age $(\mathrm{yrs})$ & $25.00 \pm 0.60$ & $23.37 \pm 0.78$ & $20.30 \pm 0.5036^{* * * \#}$ \\
\hline Weight $(\mathrm{kg})$ & $60.40 \pm 0.50$ & $58.05 \pm 0.50$ & $56.60 \pm 0.36$ \\
\hline Height $(\mathrm{cm})$ & $154.00 \pm 0.90$ & $154.00 \pm 0.60$ & $151.70 \pm 0.80$ \\
\hline Gestational age & $36.60 \pm 0.37$ & $33.63 \pm 0.23$ & $31.16 \pm 0.50$ \\
\hline Birth weight $(\mathrm{kg})$ & $3.10 \pm 0.024$ & $2.924 \pm 0.019^{* * * *}$ & $2.391 \pm 0.067^{* * *}$ \\
\hline
\end{tabular}

The values are expressed as mean and standard error of mean at "P" level of significance.

Table-2: Blood Pressure Values And Proteinuria Of Normal Pregnant And Pregnancy Induced Hypertensive Women

\begin{tabular}{|c|c|c|c|}
\hline Parameters & $\begin{array}{c}\text { Normal Cases } \\
(\mathbf{n}=\mathbf{4 0})\end{array}$ & $\begin{array}{c}\text { Mild cases } \\
(\mathbf{n}=\mathbf{4 0})\end{array}$ & $\begin{array}{c}\text { Severe cases } \\
(\mathbf{n}=\mathbf{3 0})\end{array}$ \\
\hline $\begin{array}{c}\text { Systolic blood } \\
\text { pressure }\end{array}$ & $121.00 \pm 1.69$ & $144.50 \pm 1.11^{* * *}$ & $172.60 \pm 3.31^{* * * \#}$ \\
\hline $\begin{array}{c}\text { Diastolic blood } \\
\text { pressure }\end{array}$ & $77.70 \pm 1.11$ & $93.00 \pm 0.80^{* * *}$ & $127.83 \pm 2.07^{* * * \#+冂}$ \\
\hline Proteinuria & $7.5(3)$ & $52.50(21)$ & $100.0(30)$ \\
\hline
\end{tabular}

The values are expressed as mean and standard error of mean at "P" level of significance.

*** $(\mathrm{P}<0.001)$ Highly significant as compared to normal pregnant women (normal cases)

\#\#\# $(\mathrm{P}<0.001)$ Highly significant as compared to mild cases of pregnancy induced hypertensive women.

** $(\mathrm{P}<0.01)$ Significant as compared to normal pregnant women. \#\# $(\mathrm{P}<0.01)$ Significant as compared to mild cases of pregnancy induced hypertensive women

Table-3: Detection Of Alpha Tocopherol Vitamin E (Mg/Dl) In Normal Pregnant And Pregnancy Induced Hypertensive Women

\begin{tabular}{|l|c|c|c|}
\hline \multicolumn{1}{|c|}{ Parameters } & $\begin{array}{c}\text { Normal cases } \\
(\mathbf{n}=\mathbf{4 0})\end{array}$ & $\begin{array}{c}\text { Mild cases } \\
(\mathbf{n}=\mathbf{4 0})\end{array}$ & $\begin{array}{c}\text { Severe cases } \\
(\mathbf{n}=\mathbf{3 0})\end{array}$ \\
\hline $\begin{array}{l}\text { Alpha tocopherol } \\
\text { Vitamin E (mg/dl) }\end{array}$ & $0.78 \pm 0.040$ & $0.74 \pm 0.03$ & $0.32 \pm 0.001^{* * * \# \#}$ \\
\hline Platelet count & $348000 \pm 574.35$ & $246820 \pm 193.51^{* *}$ & $135460 \pm 387.20^{* * \#}$ \\
\hline
\end{tabular}

*** $(\mathrm{P}<0.001)$ Highly significant as compared to normal pregnant women.

\#\#\# $(\mathrm{P}<0.001)$ Highly significant as compared to mild cases of pregnancy induced hypertensive women.

vitamin E (á-tocopherols) in PIH women point towards the probable defensive role of antioxidant nutrients in platelet aggregation and pregnancy induced hypertension. ${ }^{10}$ Among other antioxidants of human body, Vitamin E is certainly the only lipid soluble antioxidant with chain breaking ability. ${ }^{17}$

Previously declared research material specify the involvement of free radical reactions in pregnancy induced hypertension as well as in other disorders like cardiovascular diseases and neoplasia ${ }^{18}$. 
The á-tocopherol component of Vitamin E out of four tocopherols is the only class suitable for human body. It has been stated to be a phenolic antioxidant, which acts as a free peroxyl radical hunter by donating its hydrogen atom to free oxygen radicals thus rendering them inactive and non-violent for human cells. Hence, Vitamin E has a crucial role in protecting polyunsaturated fatty acids (PUFA), cell membrane components and free radical related oxidation of low density lipoprotein (LDL). ${ }^{19}$

Much documentation has been done on the effects of nutritional supplements on maternal body during different stages and conditions of pregnancy. The centre of interest in this study was the serum concentration of vitamin $\mathrm{E}$ in $\mathrm{PIH}$ and the protective role which Vitamin E played against platelet aggregation mechanism. Our findings demonstrated the decreased plasma levels of vitamin E in severe cases of pregnancy induced hypertension. Also decreased platelet levels were recorded in severe cases of PIH indicating the enhanced aggregating activity of platelets thus decreased detection in plasma. The role of vitamin $\mathrm{E}$ as inhibitor of platelet aggregation has been investigated thoroughly. Hence, this can be hypothesized that decreased plasma concentration of Vitamin E due to its consumption in oxidative stress condition in pre-eclampsia, predisposes to increased platelet aggregation, thus leading to decreased serum levels in preeclampsia. Several previous studies have also identified an association between low levels of Vitamin E along with some other antioxidants with higher chances of pre-eclamptic occurrence. A meta- analysis showed relation between low Vitamin $E$ levels and occurrence of pre-eclampsia, especially severe type of pre-eclampsia ${ }^{20}$. These trials provide more evidence regarding the activity of natural Vitamin $\mathrm{E}$ and other antioxidants in pregnancy. A case control study showed decreased incidence of pre-eclampsia in pregnant women on Vitamin supplements as compared to control group. Hence, there was $46 \%$ reduced risk of developing preeclampsia in supplement taking pregnant women. ${ }^{21} \mathrm{~A}$ prospective study done on Vitamin $\mathrm{E}$ and $\mathrm{C}$ supplementation during the early weeks of pregnancy showed decreased incident of preeclamptic development in pregnant women by improving placental function and reducing oxidative insult. Natural Vitamin E thought to be more effective because of their antioxidant properties and their role in fighting free radicals which may lead to development of pre-eclampsia ${ }^{22}$.However, some researchers have found increased levels of Vitamin E in PIH, which could be due to the compensatory mechanism taking place against increased oxidative stress ${ }^{23}$.

Decreased vitamin E levels have already been documented in malnourished population of Asian countries as compared to western population ${ }^{24}$ Also, vitamin E deficiency was found to be prevalent in South Asian pregnant women with healthy status. Bangladeshi researchers found á-tocopherol deficiency in $43.5 \%$ of the pregnant women ${ }^{25}$. A study done in India reported alarmingly high percentage of approximately $98 \%$ pregnant women deficient for vitamin $\mathrm{E}^{26}$. No direct study regarding vitamin $\mathrm{E}$ levels and its deficiency in Pakistani women was found except for a limited sized study with different objective of investigating suitable detecting method for vitamin $\mathrm{E}$, which showed low levels of vitamin $\mathrm{E}$ in $4.9 \%$ of seemingly healthy adults ${ }^{27}$. Documented statistics regarding vitamin E deficiency in Pakistani population have not been found significantly, rendering it as an unexplored issue, which needs further research. However, a small sample sized study including diagnosed $25 \mathrm{PIH}$ women was done in Karachi, which showed decreased blood pressure levels when alpha-tocopherol $400 \mathrm{mg} /$ day was administered to them from 24 weeks of gestation ${ }^{28}$. Hence, supporting the assumption of antioxidant role in decreasing the oxidative stress component in preeclampsia. Multiple antioxidant enzymes in the human body and exogenous nutrients provide defense against increasing oxidative stress and free radical damage. Several enzymes which acts as antioxidants are produced within the body, hence their production and levels cannot be manipulated easily. However, nutrients with antioxidant properties can be administered through diet and supplements to the patients.

It can be proposed that sufficient levels of antioxidants in mother can restrict the process of free radical production and lipid peroxidation, thus protecting the maternal endothelial cells ${ }^{29}$. It is recommended that antioxidant utilization in PIH should further be justified by large scale studies. Furthermore, to clearly identify the preventive role of antioxidant nutrients in averting the preeclamptic development and its related disorders, researchers should opt for nutritional intervention studies in pregnant women having history of preeclampsia.

\section{CONCLUSION:}

In patients with risk of preeclampsia adequate antioxidant nutrients may have a role in cessation of free radical-mediated cell disturbances, and thereby protecting against endothelial cell damage, which is the key factor in preeclampsia development.

\section{REFERENCES:}

1. Zeisler H, Llurba E, Chantraine F, Vatish M, Staff AC, Sennstrom M, Olovsson M, Brennecke SP, Stepan H, Allegranza D, Dilba P, Schoedl M, Hund M and Verlohren S. Predictive value of the sFlt-1: P1GF ratio in women with suspected pre-eclampsia. New Eng J Med. 2016; 374(1):1322.

2. Kathpalia SK, Arora CD and jain AA. Reversible blindness associated with pre-eclampsia - A report of three cases. J Nurs Healthcare Manag. 2018; 1:103.

3. Young BR, Levine RJ and Karumanchi A. Pathogenesis of pre-eclampsia. Annu Rev PatholMech Dis. 2010; 5:173-192.

4. Siti HN, Kamisah Y and kamsiah J. The role of oxidative stress, antioxidants and vascular inflammation in cardiovascular disease (a review). Vascular Pharmacol. 2015; 71:40-56. 
5. Mollace V, Gliozzi M, Musolino V, Carresi C, Muscoli S, Mollace R, Tavernese A, Gratteri S, Palma E, Morabito C, Vitale C, Muscoli C, Fini M and Remeo F. Oxidized LDL attenuates protective autophagy and induces apoptotic cell death of endothelial cells: Role of oxidative stress and LOX1 receptor expression. Intern J Cardiol 2015; 184:152-158.

6. Burton GJ and Jauniaux E. Oxidative stress. Best Pract Res ClinObstetGynaecol. 2011; 25:287-299.

7. Majed $\mathrm{BH}$ and Khalil RA. Molecular mechanisms regulating the vascular prostacyclin pathways and their adaptation during pregnancy and in the newborn. Pharmacol Rev 2012; 64:540582.

8. Raijmakers MTM, Dechend R and Poston L. Oxidative stress and pre-eclampsia: rationale for antioxidant clinical trials. Hypertens. 2004; 44:374-380.

9. Gohil JT, Patel PK and Priyanka G. Evaluation of oxidative stress and antioxidant defence in subjects of pre-eclampsia. J ObstetGynecol India. 2011; 61(6):638-640.

10. Rizvi S, Raza ST, Ahmed F, Ahmad A, Abbas S and Mahdi F. The role of Vitamin $\mathrm{E}$ in human health and some diseases. Sultan QaboosUni Med J. 2014; 14(2):e157-e165.

11. Mangialasche F, Kivipelto M, Mecocci P, Rizzuto D, Palmer K, Winblad B and Fratiglioni L. High plasma levels of vitamin $\mathrm{E}$ forms and reduced Alzheimer's disease risk in advanced age. J Alzheimer's Dis 2010; 20:1029-1037.

12. Mistry HD and Williams PJ. The importance of antioxidant micronutrients in pregnancy. Oxidative Med Cell Longevity 2011; 2011:12 pages.

13. Suleiman AK. Risk factors on hypertensive disorders among Jordanian pregnant women. Global J Health Sci. 2014; 6(2):138-144.

14. Chappell LC, Seed PT, Briley AL, Kelly FJ, Lee R, Hunt BJ, Parmar K, Bewley SJ, Shennan AH, Steer PJ and Poston L. Effect of antioxidants on the occurrence of pre-eclampsia in women at increased risk: a randomized trial. The Lancet 1999; 354:810-816.

15. Varga-Szabo D, Pleines I and Nieswandt B. Cell adhesion mechanisms in platelets. ArteriosclerThrombVasc Biol. 2008; 28:403-412.

16. Deanfield JE, halcox JP and Rabelink TJ. Endothelial function and dysfunction testing and clinical relevance. Circulation 2007; 115:1285-1295.

17. Valko M, Leibfritz D, Moncol J, Cronin MTD, Mazur M and Telser J. Free radicals and antioxidants in normal physiological functions and human disease. Intern J Biochem Cell Biol. 2007; 39:44-84.
18. Sharma JB, Sharma A, Bahadur A, Vimala N, Satyam A and Mittal S. Oxidative stress markers and antioxidant levels in normal pregnancy and pre-eclampsia. Intern J Gynecol Obstet. 2006; 94:23-27.

19. Traber MG and Atkinson J. Vitamin E, antioxidant and nothing more. Free RadicBiol Med. 2007; 43(1):4-15.

20. Cohen JM, Beddaoul M, Kramer MS, Platt RW, Basso O and Kahn SR. Maternal antioxidant levels in pregnancy and risk of pre-eclampsia and small for gestational age birthL: A systematic review and meta-analysis. PLoS ONE 2015; 10(8):e0135192.

21. Cardoso PM and Surve S. The effect of vitamin E and Vitamin $\mathrm{C}$ on the prevention of pre-eclampsia and newborn outcome: A case control stuidy. J ObstetGynecol India. 2016; 66(S1):S271-S278.

22. Chappell LC, Seed PT, Kelly FJ, Briley A, Hunt BJ, CharnockJones S, Mallet $\mathrm{A}$ and poston L. Vitamin $\mathrm{C}$ and $\mathrm{E}$ supplementation in women at risk of pre-eclampsia is associated with changes in indices of oxidative stress and placental function. Am J ObstetGynecol 2002; 187:777-784.

23. Kaur G, Mishra S, Sehgal A and Prasad R. Alterations in lipid peroxidation and antioxidant status in pregnancy with preeclampsia. Mol Cell Biochem. 2008; 313(1-2):37-44

24. Jilani T and Iqbal MP. Vitamin E deficiency in South Asian population and the therapeutic use of alpha-tocopherol (Vitamin E) for correction of anemia. Pak J Med Sci. 2018; 34(6):1571.

25. Shamim AA, Schulze K, Merrill RD, Kabir A, Christian P, Shaikh S, Wu L, Ali H, Labrique AB, Mehra S, Klenm RDW, Rashid M, Sungpuag P, Udomkesmalee E and West KP. First trimester plasma tocopherols are associated with risk of miscarriage in rural Bangladesh. Am J ClinNutr. 2015; 101:294301.

26. Lohia N, Udipi S, Ghugre P and Deshpande K. Serum retinol, á-tocopherol, and lipid peroxide concentrations in low income Indian pregnant mothers. Int J VitamNutr Res. 2009; 79(3):142151.

27. Mehbooali N and Iqbal MP. A simple micro method for determination of plasma levels of alpha tocopherol (Vitamin E) in Pakistani normal adults. Pak J Pharm Sci. 21(4):361365 .

28. Bashir S, Hasan SS, Ahmed SN and basar T. Role of alpha tocopherol as an adjuvant therapy in pregnancy induced hypertension. Pak J Pharmacol. 2011; 28(2):59-64.

29. Campbell S. and Lees C. Disorders of placentation in Obstetrics by Ten Teachers $17^{\text {th }}$ ed, London, Arnold, 2000; pp.157-158. 